\title{
TOlerÂNCIA de HÍbridos de MILHO AO HeRBICIdA IsOXAFlutole ${ }^{1}$
}

\author{
Tolerance of Corn Hybrids to Isoxaflutole
}

\author{
CAVALIERI, S.D. ${ }^{2}$, OLIVEIRA JR., R.S. ${ }^{3}$, CONSTANTIN, J. ${ }^{3}$, BIFFE, D.F. ${ }^{4}$, DVORANEN, E.C. ${ }^{5}$ \\ e BLAINSKI, E. ${ }^{6}$
}

\begin{abstract}
RESUMO - Objetivou-se com este trabalho avaliar a tolerância de híbridos de milho ao isoxaflutole e relacionar estudos de seletividade desse herbicida conduzidos em casa de vegetação com estudos desenvolvidos em campo. Em casa de vegetação, o experimento foi conduzido no delineamento de blocos ao acaso, num arranjo fatorial de $23 \times 3$, sendo o primeiro fator constituído por híbridos de milho e o segundo por doses do herbicida $(0,60$ e $120 \mathrm{~g} \mathrm{ha}^{-1}$ ). Após a aplicação do herbicida, avaliou-se a massa seca de parte aérea das plantas. Em campo, o experimento foi conduzido no delineamento de blocos ao acaso, em arranjo fatorial de $5 \times 3$, em que os fatores foram constituidos por cinco híbridos de milho, selecionados a partir dos resultados em casa de vegetação, e três doses herbicidas $(0,60$ e $120 \mathrm{~g} \mathrm{ha}^{-1}$ ). Após a aplicação do herbicida, foram avaliados o crescimento e a produtividade dos híbridos. Por meio dos resultados obtidos em casa de vegetação, foi possivel agrupar os híbridos em diferentes níveis de tolerância ao herbicida. Com relação à produtividade de grãos, não foi constatada interação significativa entre os híbridos e as doses herbicidas. No entanto, na média de todos os híbridos avaliados, houve efeito negativo do isoxaflutole na dose de $120 \mathrm{~g} \mathrm{ha}^{-1}$ sobre a produtividade do milho. Assim, ao avaliar a seletividade do isoxaflutole em híbridos de milho, é necessária a etapa de campo para verificar se os tratamentos herbicidas têm influência sobre a produtividade de grãos.
\end{abstract}

Palavras-chave: inibidores da síntese de carotenóides, isoxazoles, seletividade, Zea mays.

\begin{abstract}
This research aimed to evaluate the tolerance of corn hybrids to isoxaflutole and to correlate greenhouse selectivity studies to field studies for this herbicide. Under greenhouse conditions, experiments were arranged in a randomized block design, in a $23 \times 3$ factorial scheme, with the first factor being corn hybrids and the second factor herbicide rates $\left(0,60\right.$ and $\left.120 \mathrm{~g} \mathrm{ha}^{-1}\right)$. Treatment effect was evaluated based on shoot biomass. Under field conditions, a randomized block design experiment was carried out, in a factorial scheme $5 \times 3$ (five corn hybrids, selected from the greenhouse studies, and three herbicide rates $\left(0,60\right.$ and $\left.120 \mathrm{~g} \mathrm{ha}^{-1}\right)$. Field results were evaluated based on crop development and yield. Based on the greenhouse experiments, corn hybrids were grouped according to tolerance to isoxaflutole. No significant correlation was found between hybrids and corn rates in relation to grain yield in the field. Otherwise, average grain yield across all hybrids was decreased by isoxaflutole at $120 \mathrm{~g} \mathrm{ha}^{-1}$. It was concluded that greenhouse experiments are not sufficient when evaluating selectivity of isoxaflutole to corn hybrids and that field trials should be taken into account to evaluate the effects on crop yield.
\end{abstract}

Keywords: pigment inhibitors, isoxazoles, selectivity, Zea mays

1 Recebido para publicação em 22.8.2007 e na forma revisada em 5.3.2008

Parte da dissertação do primeiro autor apresentada ao Programa de Pós-Graduação em Agronomia da Universidade Estadual de Maringá para obtenção do título de Mestre em Agronomia, área de concentração em Proteção de Plantas

2 Engo-Agr ${ }^{\circ}$, M.Sc., Doutorando em Agronomia (Agricultura) pela Faculdade de Ciências Agronômicas da Universidade Estadual Paulista "Júlio de Mesquita Filho", FCA/UNESP, Caixa Postal 237, 18603-907 Botucatu-SP, <cavalieri@fca. unesp.br>; ${ }^{3}$ Professor Associado, Núcleo de Estudos Avançados em Ciência das Plantas Daninhas (NAPD/UEM), Dep. de Agronomia, Universidade

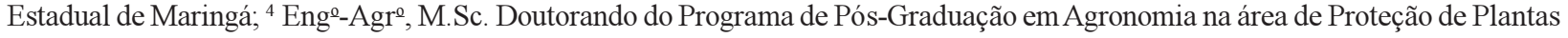
(NAPD/UEM); ${ }^{5}$ Eng-0-Agr ${ }^{\circ}$, M.Sc., (NAPD/UEM); ${ }^{6}$ Graduando em Agronomia (NAPD/UEM). 


\section{INTRODUÇÃO}

O isoxaflutole [5-ciclopropil-4-(2-metilsulfonil-4-trifluorometilbenzoil)-isoxaflutole, do grupo químico dos isoxazóis é considerado um pró-herbicida, uma vez que no solo, na água e na planta é rapidamente convertido em metabólito diquetonitrila, que é a molécula biologicamente ativa no controle de plantas daninhas, por meio da clivagem do anel isoxazole (Cezarino, 1997). No caso do solo, quanto maior a umidade e o $\mathrm{pH}$, mais rápida é a conversão. Segundo Rouchaud et al. (1998), a dissipação do isoxaflutole em diquetonitrila é mais rápida em $\mathrm{pH}$ 7,2 do que em $\mathrm{pH}$ 5,5. O metabólito diquetonitrila é mais solúvel, estável e persistente que o isoxaflutole e apresenta solubilidade em água de $326 \mathrm{mg} \mathrm{L}^{-1}$ (Mitra et al., 2000; Taylor-Lovell et al., 2000, 2002). Taylor-Lovell et al. (2002) relatam meia-vida maior que 56 dias em solo com pH 7,0 e 2,5\% de carbono orgânico para o diquetonitrila, comparado à meia-vida menor que dois dias para o isoxaflutole no mesmo solo.

Atualmente, o isoxaflutole é recomendado para controle de gramineas anuais e perenes, propagadas por meio de sementes, e algumas plantas de folhas largas em milho, mandioca, batata, algodão e cana-de-açúcar (Rodrigues \& Almeida, 2005). Nessas culturas, esse herbicida pode ser usado em pré e pósemergência precoce (Kruse, 2001).

O isoxaflutole causa a disrupção da sintese de pigmentos, levando ao surgimento de sintomas característicos de "branqueamento" de tecidos desenvolvidos após a aplicação nas espécies suscetíveis, seguido de paralisação de crescimento e necrose (Pallet et al., 1998). Esse "branqueamento" ocorre devido à fotoxidação e destruição da clorofila, provocada pela presença de luz e ausência de carotenóides, que não exercem seu papel protetor contra a fotoxidação (Devine et al., 1993; Vidal, 1997; Sprague et al., 1999b).

O isoxaflutole é absorvido preferencialmente pelas raizes, embora o seja também pelas sementes. Isso não ocorre com seu derivado diquetonitrila, que é absorvido somente pelas raízes. Sprague et al. (1999a) verificaram que, em sementes, o isoxaflutole é mais prontamente absorvido que o diquetonitrila. Após absorvido, tanto o isoxaflutole como o diquetonitrila são transportados rapidamente para o ápice da plântula, onde a maior parte do isoxaflutole é então convertida em diquetonitrila. Estudos com aplicações de isoxaflutole sobre as folhas mostraram que ocorre absorção foliar e posterior translocação, evidenciando mobilidade simplástica e apoplástica desse herbicida e do seu principal metabólito (Sprague et al., 1999b; Young \& Hart, 2000).

A grande responsável pela seletividade do isoxaflutole para espécies tolerantes, como o milho e a cana-de-açúcar, é a capacidade de metabolizar rapidamente o isoxaflutole para diquetonitrila e, principalmente, deste para ácido benzóico, que não possui qualquer ação herbicida, e, ao final do processo, para gás carbônico (Pallet et al., 1998; Sprague et al., 1999b). Em espécies sensiveis, essa metabolização ocorre lentamente, permitindo a inibição enzimática pelo diquetonitrila. Parece não haver diferenças na absorção e translocação entre milho e plantas sensiveis, com o diquetonitrila sendo translocado através de toda a planta para folhas novas e formadas, predominantemente, pela rota apoplástica. A redistribuição de diquetonitrila de folhas maduras para folhas jovens via floema deve também ocorrer (Pallet et al., 1998).

Segundo Kruse (2001), os carotenóides têm a função de dissipar o excesso de energia da clorofila na forma de calor e evitar a formação de clorofila tripleno, estado este caracterizado quando a clorofila, na presença de luz, forma radicais livres. Na presença dos herbicidas inibidores da síntese de carotenóides ocorre acúmulo de radicais livres, com conseqüente destruição das membranas celulares e posterior morte das plantas.

A maioria dos herbicidas inibidores da sintese de carotenóides, no entanto, atua sobre a fitoeno desaturase, enzima que catalisa as reações iniciais na conversão do fitoeno (precursor incolor dos carotenóides) em carotenóides coloridos. Os sintomas foliares estão associados com o acúmulo do fitoeno, típico dos herbicidas que inibem a fitoeno desaturase. No entanto, nem o isoxaflutole nem o diquetonitrila inibem a atividade desta enzima. $\mathrm{O}$ diquetonitrila inibe a 4-hidroxifenil-piruvato dioxigenase (HPPD) a partir da degradação do aminoácido tirosina, com inibição indireta da 
fitoeno desaturase resultante da depleção de um co-fator essencial, a plastoquinona (Pallet et al., 1998; Viviani et al., 1998).

Embora a conversão de isoxaflutole em diquetonitrila possa ocorrer antes ou após a absorção pelas plantas, é o metabólito diquetonitrila que atua como um potente inibidor da HPPD. O isoxaflutole bloqueia também o transporte de elétrons da fotossintese, em nivel de fotossistema II, pela menor produção de plastoquinona necessária ao transporte de elétrons, gerando o estado de clorofila tripleno e os demais radicais livres, aumentando, assim, o estresse oxidativo já provocado pela ausência de proteção dos carotenóides (Devine et al., 1993; Pallet et al., 1998; Viviane et al., 1998).

Assim, mesmo o isoxaflutole sendo um herbicida registrado para a cultura do milho, diversos problemas de fitointoxicação na cultura têm sido descritos após o seu uso. Até o momento, não se chegou a fatos conclusivos que explicassem os motivos pelos quais isso esteja ocorrendo. Fatores relacionados à sensibilidade de híbridos, à composição química e física do solo onde o herbicida é aplicado ou ainda à intensidade de precipitação pluvial que ocorre após a semeadura podem estar envolvidos.

Em decorrência dos sintomas de fitointoxicação apresentados pela cultura do milho após a utilização desse herbicida, o presente traba1ho foi elaborado com o propósito de avaliar a tolerância de híbridos de milho ao isoxaflutole, em vista da limitada disponibilidade de informações existentes quanto à sua seletividade à cultura, bem como relacionar estudos de seletividade desse herbicida conduzidos em casa de vegetação com estudos desenvolvidos em campo, no que se refere ao desenvolvimento e à produtividade dos híbridos.

\section{MATERIAL E MÉTODOS}

Este trabalho foi composto por duas etapas: a primeira foi conduzida em casa de vegetação do Núcleo de Estudos Avançados em Ciência das Plantas Daninhas da Universidade Estadual de Maringá (NAPD/UEM), no município de Maringá, PR; e a segunda, em campo, em uma propriedade localizada a aproximadamente $2 \mathrm{~km}$ da Fazenda Experimental de Iguatemi
(FEI), no municipio de Iguatemi, PR, pertencente à Universidade Estadual de Maringá. Segundo a classificação de Köppen, o clima para ambas as localidades é do tipo CW'a, mesotérmico úmido, com chuvas de verão e de outono e verão quente.

\section{Experimento em casa de vegetação}

Foram utilizadas amostras deformadas de solo, provenientes da camada de 0 a 0,20 $\mathrm{m}$ de profundidade de um Argissolo Vermelho distrófico (Embrapa, 1999) de textura arenosa com 95\% de areia, $2 \%$ de silte e $3 \%$ de argila. A análise química apresentou $\mathrm{pH}$ em $\mathrm{H}_{2} \mathrm{O}=6,5$; $\mathrm{Al}^{3+}, \mathrm{H}^{+}+\mathrm{Al}^{3+}, \mathrm{Ca}^{2+}, \mathrm{Mg}^{2+}$ e $\mathrm{K}^{+}$de 0,$0 ; 1,88 ; 1,48$; 0,59 ; e $0,16 \mathrm{cmol}_{\mathrm{c}} \mathrm{dm}^{-3}$, respectivamente; $\mathrm{P}=$ $51,0 \mathrm{mg} \mathrm{dm}^{-3}$; e C $=5,58 \mathrm{~g} \mathrm{dm}^{-3}$.

As amostras foram coletadas em área com conhecido histórico de uso sob semeadura direta, em que na safra de verão anterior havia sido cultivado soja na área; posteriormente, na entressafra, a área ficou em pousio. Após a coleta das amostras, o solo foi peneirado em malha de $2 \mathrm{~mm}$, para separação de torrões, raízes e palha. $\mathrm{O}$ experimento foi conduzido no período de 9/10/2004 a 10/11/2004.

As unidades experimentais foram constituídas por vasos com capacidade de $5 \mathrm{dm}^{3}$, onde foram semeadas seis sementes de milho por vaso, à profundidade de aproximadamente $2 \mathrm{~cm}$, aplicando o isoxaflutole a seguir em préemergência. A semeadura foi efetuada com sementes tratadas com imidacloprid na dose de 480 g para cada $100 \mathrm{~kg}$ de sementes. Após a emergência das plantas, procedeu-se ao desbaste, deixando apenas três plantas por vaso.

Quanto às aplicações do isoxaflutole, utilizou-se pulverizador costal pressurizado com $\mathrm{CO}_{2}$, com pressão constante de $207 \mathrm{kPa}$, equipado com três pontas XR 110.02, espaçadas de $0,5 \mathrm{~m}$ entre si e posicionadas a $0,5 \mathrm{~m}$ da superfície do alvo, aplicando-se o equivalente a $200 \mathrm{~L} \mathrm{ha}^{-1}$ de calda. As condições no momento da aplicação dos tratamentos foram de céu claro, velocidade do vento inferior a $5 \mathrm{~km} \mathrm{~h}^{-1}$, solo úmido, temperatura do ar de $23{ }^{\circ} \mathrm{C}$ e umidade relativa de $86 \%$.

No experimento foram avaliados 23 híbridos de milho provenientes de diferentes empresas: AG 6040, AG 9010, B 178, B 184, 
B 551, B 761, BRS 2114, BRS 2160, BRS 3003, BRS 3150, CD 304, CD 306, CD 307, CD 308, Ocepar 705, Fort, Garra, Penta, Pointer, Premium-Flex, Speed, Tork e Valente.

Eles foram combinados em esquema fatorial com três doses do herbicida isoxaflutole $\left(0,60\right.$ e $\left.120 \mathrm{~g} \mathrm{ha}^{-1}\right)$, num delineamento em blocos ao acaso com quatro repetições, totalizando 276 unidades experimentais.

Avaliou-se a massa seca da parte aérea das plantas de cada vaso aos 32 DAA, sendo ela obtida a partir da colheita do material vegetal presente nos vasos, utilizando-se estufa a $70{ }^{\circ} \mathrm{C}$ por 48 horas. A avaliação de massa seca foi corrigida para valores percentuais por meio da comparação dos valores obtidos nos tratamentos herbicidas com os valores da testemunha sem herbicida, considerada $100 \%$.

Os dados foram submetidos aos testes de Levene e Shapiro-Wilk, com o objetivo de avaliar a variância e a normalidade dos erros, utilizando-se o programa estatístico SAS (SAS, 1999). Para análise dos dados, utilizou-se análise de variância, e as médias foram comparadas pelo teste de agrupamento Scott-Knott a $5 \%$ de probabilidade, utilizando-se o programa estatístico SISVAR (Ferreira, 1999).

\section{Experimento em campo}

O ensaio foi instalado em solo identificado como Argissolo Vermelho distrófico (Embrapa, 1999) de textura areia franca com $75 \%$ de areia, $8 \%$ de silte e $17 \%$ de argila. A análise química apresentou $\mathrm{pH}$ em $\mathrm{H}_{2} \mathrm{O}=5,7 ; \mathrm{Al}^{3+}$, $\mathrm{H}^{+}+\mathrm{Al}^{3+}, \mathrm{Ca}^{2+}, \mathrm{Mg}^{2+}$ e K' , de 0,0; 3,58; 4,00; 1,92; e $\quad 0,51 \mathrm{cmol}_{c} \mathrm{dm}^{-3}, \quad$ respectivamente; $\mathrm{P}=3,0 \mathrm{mg} \mathrm{dm}^{-3} ; \mathrm{e} \mathrm{C}=6,97 \mathrm{~g} \mathrm{dm}^{-3}$.

Antes da instalação dos experimentos, as plantas daninhas presentes na área foram manejadas com dessecações seqüenciais, visando semeadura no limpo. A primeira aplicação foi realizada com a mistura de $720 \mathrm{~g}^{\mathrm{ha}^{-1}}$ de glyphosate $+24 \mathrm{~g} \mathrm{ha}^{-1}$ de carfentrazone-ethyl 20 dias antes da semeadura, e a segunda, com $400 \mathrm{~g} \mathrm{ha}^{-1}$ de paraquat no dia da semeadura. Todas as plantas daninhas que emergiram durante o ciclo da cultura foram eliminadas por capina manual, independentemente do controle proporcionado pelas aplicações herbicidas.

Planta Daninha, Viçosa-MG, v. 26, n. 4, p. 901-909, 2008
A semeadura foi realizada no dia 26 de novembro de 2005, em sistema de semeadura direta; imediatamente antes da sua realização, foram formados sulcos espaçados de $0,90 \mathrm{~m}$ entre si, utilizando uma semeadora, os quais receberam o equivalente a $300 \mathrm{~kg} \mathrm{ha}^{-1}$ do adubo formulado 08-20-20. Nesses sulcos foram semeadas manualmente seis sementes de milho por metro, a uma profundidade de 2$5 \mathrm{~cm}$, aplicando-se o isoxaflutole a seguir em pré-emergência. Cada unidade experimental foi constituída por seis linhas de $5 \mathrm{~m}$ de comprimento, perfazendo uma área de $30 \mathrm{~m}^{2}$. Considerou-se como área útil as quatro linhas centrais, descontado $0,5 \mathrm{~m}$ de cada extremidade $\left(14,4 \mathrm{~m}^{2}\right)$. A emergência do milho teve início cinco dias após a semeadura, no dia $1^{\circ}$ de dezembro de 2005.

O herbicida isoxaflutole foi aplicado com pulverizador costal pressurizado com $\mathrm{CO}_{2}$, nas mesmas condições operacionais do experimento anterior, com o isolamento de cada parcela com cortinas plásticas no momento da aplicação. As condições no momento da aplicação dos tratamentos foram de céu claro, velocidade do vento inferior a $5 \mathrm{~km} \mathrm{~h}^{-1}$, solo úmido, temperatura do ar de $28^{\circ} \mathrm{C}$ e umidade relativa de $55 \%$.

Para compor os tratamentos avaliados no campo, foram utilizados cinco híbridos de milho, escolhidos previamente a partir dos resultados de casa de vegetação. Selecionaram-se híbridos com diferentes niveis de sensibilidade ao herbicida isoxaflutole, os quais foram divididos em três grupos, levando-se em consideração o acúmulo de massa seca de parte aérea após a aplicação do herbicida: o primeiro, de alta sensibilidade, composto pelos híbridos Penta e Ocepar 705; o segundo, de sensibilidade intermediária, composto pelos híbridos $C D$ 304 e B 184; e o terceiro, de baixa sensibilidade, composto pelo híbrido Garra.

$\mathrm{O}$ experimento foi realizado em esquema fatorial $5 \times 3$, composto por cinco híbridos de milho (Penta, B 184, CD 304, Ocepar 705 e Garra) combinados com três doses do herbicida isoxaflutole $\left(0,60\right.$ e $\left.120 \mathrm{~g} \mathrm{ha}^{-1}\right)$, sendo a primeira dose considerada testemunha, num delineamento em blocos ao acaso com seis repetições, totalizando 90 unidades experimentais.

As avaliações foram constituídas pela fitointoxicação das plantas, utilizando-se escala 
visual de $0-100 \%$, em que 0 corresponde a nenhum tipo de injúria e 100 à morte das plantas aos 7, 14, 21 e 28 DAA; pela altura aos 21 e 28 DAA, medindo-se dez plantas por parcela, desde a superficie do solo até a inserção da lígula da última folha expandida; pelo diâmetro de colmo de dez plantas por parcela por ocasião do surgimento das espigas aos 77 DAA, realizada com auxílio de paquímetro digital, sendo a leitura realizada no primeiro entrenó abaixo da espiga mais baixa; e pela produtividade, corrigida para $14 \%$ de umidade. No cálculo da umidade dos grãos utilizou-se um valor médio de quatro avaliações de umidade por parcela, por meio da seguinte fórmula: $\mathrm{U}(\%)=[(\mathrm{MU}-\mathrm{MS}) /$ $\mathrm{MU}] \times 100$, em que U(\%) é a umidade em porcentagem, MU é a massa dos grãos úmidos e MS é a massa dos grãos secos. Para efeito de análise, os dados de diâmetro de colmo e altura aos 28 DAA foram transformados para $\log (\mathrm{x})$. A colheita foi feita em 6 de abril de 2006. As espigas foram despalhadas manualmente e debulhadas mecanicamente.

Os dados foram submetidos aos testes de Levene e Shapiro-Wilk, com o objetivo de avaliar a variância e a normalidade dos erros, empregando-se o programa estatístico SAS (SAS, 1999). Na análise dos dados empregou-se análise de variância, e as médias foram comparadas pelo teste de Tukey a $5 \%$ de probabilidade, utilizando-se o programa estatístico SISVAR (Ferreira, 1999).

\section{RESULTADOS E DISCUSSÃO}

\section{Experimento em casa de vegetação}

A massa seca de parte aérea das plantas de milho tratadas com o herbicida isoxaflutole (Tabela 1), aos 32 DAA, evidencia que, quando comparados às suas respectivas testemunhas sem herbicida, apenas os híbridos BRS 2114, CD 304, Garra e Penta mostraram redução significativa em ambas as doses herbicidas avaliadas; para os híbridos BRS 2114 e Penta essa diferença foi significativa também entre as doses de 60 e $120 \mathrm{~g} \mathrm{ha}^{-1}$, observando-se maior redução na dose de $120 \mathrm{~g} \mathrm{ha}^{-1}$. No entanto, quando aplicada a dose de $120 \mathrm{~g} \mathrm{ha}^{-1}$, além destes, os híbridos AG 6040, B 184, BRS 2160, CD 306, Ocepar 705, Premium - Flex e Valent também apresentaram redução.
Tabela 1 - Produção de massa seca relativa de parte aérea (\%) em relação à testemunha das plantas de híbridos de milho submetidos ao herbicida isoxaflutole aos 32 dias após a aplicação (DAA) em casa de vegetação. Universidade Estadual de Maringá, Maringá-PR, 2007

\begin{tabular}{|c|c|c|c|}
\hline \multirow{2}{*}{ Híbrido } & \multicolumn{3}{|c|}{ Dose $\left(\mathrm{g} \mathrm{ha}^{-1}\right)$} \\
\hline & 0 & 60 & 120 \\
\hline AG 6040 & $100,0 \mathrm{Aa}$ & $93,33 \mathrm{Aa}$ & $73,86 \mathrm{Ba}$ \\
\hline AG 9010 & $100,0 \mathrm{Aa}$ & $87,03 \mathrm{Aa}$ & $81,95 \mathrm{Aa}$ \\
\hline B 178 & $100,0 \mathrm{Aa}$ & $90,73 \mathrm{Aa}$ & $77,21 \mathrm{Aa}$ \\
\hline B 184 & $100,0 \mathrm{Aa}$ & $89,54 \mathrm{Aa}$ & $70,42 \mathrm{Bb}$ \\
\hline B 551 & $100,0 \mathrm{Aa}$ & $97,28 \mathrm{Aa}$ & $92,51 \mathrm{Aa}$ \\
\hline В 761 & $100,0 \mathrm{Aa}$ & $89,98 \mathrm{Aa}$ & $83,36 \mathrm{Aa}$ \\
\hline BRS 2114 & $100,0 \mathrm{Aa}$ & $81,16 \mathrm{Ba}$ & $49,29 \mathrm{Cc}$ \\
\hline BRS 2160 & $100,0 \mathrm{Aa}$ & $90,62 \mathrm{Aa}$ & $69,44 \mathrm{Bb}$ \\
\hline BRS 3003 & $100,0 \mathrm{Aa}$ & $95,71 \mathrm{Aa}$ & $84,54 \mathrm{Aa}$ \\
\hline BRS 3150 & $100,0 \mathrm{Aa}$ & $89,83 \mathrm{Aa}$ & $78,53 \mathrm{Aa}$ \\
\hline CD 304 & $100,0 \mathrm{Aa}$ & $82,29 \mathrm{Ba}$ & $67,23 \mathrm{Bb}$ \\
\hline CD 306 & $100,0 \mathrm{Aa}$ & $91,08 \mathrm{Aa}$ & $65,69 \mathrm{Bb}$ \\
\hline CD 307 & $100,0 \mathrm{Aa}$ & $86,58 \mathrm{Aa}$ & $91,45 \mathrm{Aa}$ \\
\hline CD 308 & $100,0 \mathrm{Aa}$ & $95,79 \mathrm{Aa}$ & $86,28 \mathrm{Aa}$ \\
\hline Fort & $100,0 \mathrm{Aa}$ & $85,07 \mathrm{Aa}$ & $80,93 \mathrm{Aa}$ \\
\hline Garra & $100,0 \mathrm{Aa}$ & $80,45 \mathrm{Ba}$ & $80,53 \mathrm{Ba}$ \\
\hline Ocepar 705 & $100,0 \mathrm{Aa}$ & $82,04 \mathrm{Aa}$ & $57,19 \mathrm{Bc}$ \\
\hline Penta & $100,0 \mathrm{Aa}$ & $72,82 \mathrm{Ba}$ & $48,37 \mathrm{Cc}$ \\
\hline Pointer & $100,0 \mathrm{Aa}$ & $83,08 \mathrm{Aa}$ & $85,95 \mathrm{Aa}$ \\
\hline Premium - flex & $100,0 \mathrm{Aa}$ & $90,53 \mathrm{Aa}$ & $70,09 \mathrm{Bb}$ \\
\hline Speed & $100,0 \mathrm{Aa}$ & $97,32 \mathrm{Aa}$ & $90,09 \mathrm{Aa}$ \\
\hline Tork & $100,0 \mathrm{Aa}$ & $91,66 \mathrm{Aa}$ & $88,67 \mathrm{Aa}$ \\
\hline Valent & $100,0 \mathrm{Aa}$ & $92,41 \mathrm{Aa}$ & $76,65 \mathrm{Ba}$ \\
\hline
\end{tabular}

Médias seguidas pela mesma letra, maiúscula na linha e minúscula na coluna, não diferem entre si pelo teste de Scott-Knott a 5\% de probabilidade.

O teste de Scott-Knott permitiu o agrupamento de médias semelhantes para tal variável-resposta. Assim, não foram constatadas diferenças significativas entre os híbridos quando aplicada a dose de $60 \mathrm{~g} \mathrm{ha}^{-1}$. No entanto, quando submetidos à dose de $120 \mathrm{~g} \mathrm{ha}^{-1}$, foram formados três grupos em ordem decrescente de sensibilidade: o primeiro, composto pelos híbridos Penta, BRS 2114 e Ocepar 705, que apresentaram reduções de massa seca de parte aérea de $48,37,49,29$ e $57,19 \%$, respectivamente; o segundo, composto pelos híbridos B 184, BRS 2160, CD 304, CD 306 e Premium - Flex, com reduções entre 29,58 e 34,31\%; e o terceiro, composto pelos híbridos AG 6040, 
AG 9010, B 178, B 551, B 761, BRS 3003, BRS 3150, CD 307, CD 308, Fort, Garra, Pointer, Speed, Tork e Valent, com reduções $\leq 26,14 \%$.

Todavia, nas condições em que o experimento foi conduzido, mediante os resultados do teste de agrupamento feito na dose de $120 \mathrm{~g} \mathrm{ha}^{-1}$, podem-se classificar os híbridos como: de alta sensibilidade, composto pelos híbridos BRS 2114, Ocepar 705 e Penta; de sensibilidade intermediária, composto pelos híbridos B 184, BRS 2160, CD 304, CD 306 e Premium - Flex; e de baixa sensibilidade, composto pelos híbridos AG 6040, AG 9010, B 178, B 551, B 761, BRS 3003, BRS 3150, CD 307, CD 308, Fort, Garra, Pointer, Speed, Tork e Valent; entre estes últimos, exceto o híbrido Garra, todos se destacaram como tolerantes, pois, mesmo submetidos a uma dose duas vezes maior que a recomendada, não apresentaram injúrias importantes que pudessem comprometer o acúmulo de massa seca de parte aérea.

Algumas hipóteses podem ser levantadas para esclarecer os possiveis mecanismos de tolerância de híbridos de milho ao isoxaflutole; entre elas, sugere-se a maior ou menor atividade de enzimas monoxigenases dependentes do citocromo P-450, glutationa S-transferase (GSTs), esterases e UDP-glicosiltransferases, responsáveis pela desintoxicação de herbicidas (Ferreira \& Cataneo, 2002). Outras hipóteses possiveis sugerem a absorção e translocação diferencial do herbicida para o sítio de ação na planta, com maior ou menor capacidade de metabolização e desintoxicação (Ezra \& Grassel, 1982).

\section{Experimento em campo}

A aplicação do isoxaflutole em pré-emergência, de modo geral, causou nas plantas de milho sintomas de fitointoxicação, que se caracterizaram pelo branqueamento dos tecidos com eventuais necroses, principalmente nas folhas recém-expandidas, nos primeiros dias do ciclo. Para todos os híbridos avaliados, tais sintomas ficaram mais evidentes com o incremento da dose aplicada (Figura 1). Esses sintomas são típicos de herbicidas do grupo dos isoxazóis e ocorrem devido ao bloqueio da síntese dos pigmentos carotenóides. Embora o crescimento das partes novas seja desprovido de pigmentação, esses herbicidas não inibem
7 DAA

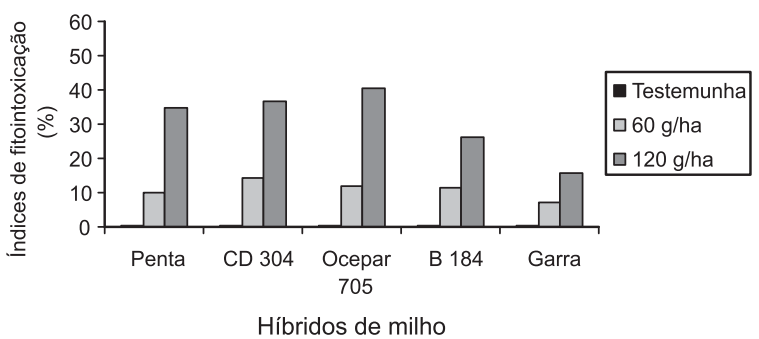

14 DAA

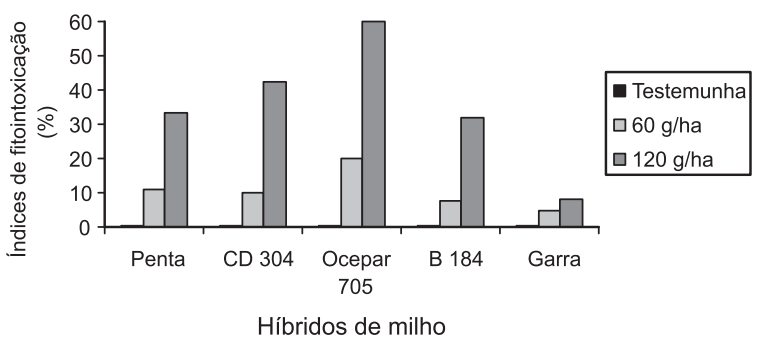

21 DAA

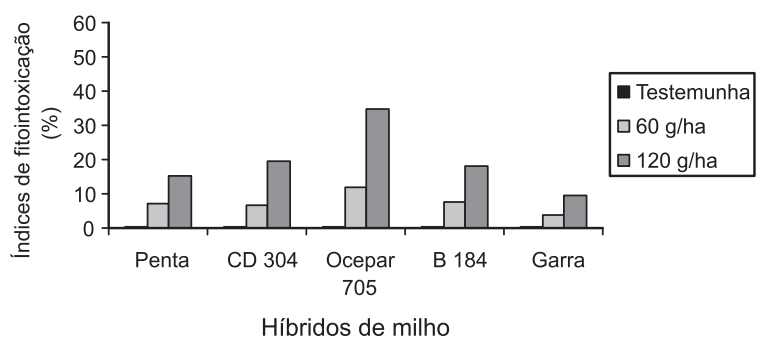

28 DAA

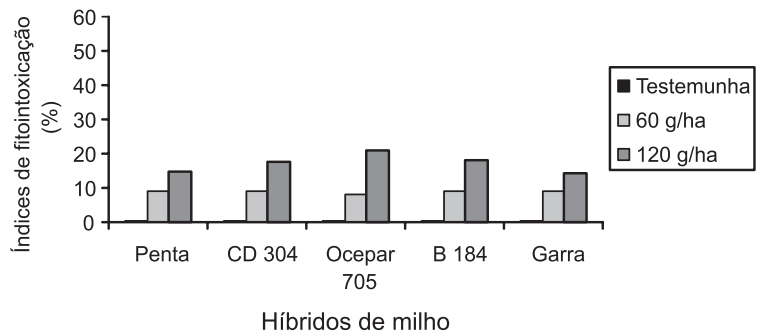

Figura 1 - Índices de fitointoxicação (\%), em quatro épocas de avaliação, de híbridos de milho submetidos à aplicação do herbicida isoxaflutole em condições de campo. Universidade Estadual de Maringá, Maringá-PR, 2007. 
diretamente a biossintese de clorofila. A perda da clorofila é resultado da sua oxidação pela luz, devido à falta de carotenóides que a protejam da fotoxidação (Devine et al., 1993; Sprague et al., 1999b; Vidal, 1997).

Em relação às doses estudadas, foram observados, somente para o híbrido Ocepar 705, indices de fitointoxicação em torno de 10 e $20 \%$ para as doses de 60 e $120 \mathrm{~g} \mathrm{ha}^{-1}$, respectivamente, nas avaliações realizadas, exceto para a última delas (28 DAA), na dose de $60 \mathrm{~g} \mathrm{ha}^{-1}$ (Figura 1). Por outro lado, o híbrido Garra foi o único que apresentou índices de fitointoxicação inferiores a 10 e $20 \%$ para as doses de 60 e $120 \mathrm{~g} \mathrm{ha}^{-1}$, respectivamente, em todas as avaliações (Figura 1).

Para a altura de plantas (Tabela 2), tanto na dose de $60 \mathrm{~g} \mathrm{ha}^{-1}$ quanto na de $120 \mathrm{~g} \mathrm{ha}^{-1}$, os híbridos CD 304 e Garra apresentaram redução significativa se comparado às suas respectivas testemunhas sem herbicida aos 21 e 28 DAA. Os demais híbridos tiveram a altura afetada pela maior dose nas diferentes épocas avaliadas.

$\mathrm{Na}$ avaliação de diâmetro de colmo (Tabela 3), na dose de $120 \mathrm{~g} \mathrm{ha}^{-1}$, foi observada somente para o híbrido Ocepar 705 redução significativa em relação à testemunha não tratada. Provavelmente esse fato tenha ocorrido em virtude de um efeito prejudicial dessa dose herbicida sobre o acúmulo de fotoassimilados no colmo.

No que se refere ao efeito dos tratamentos sobre a produtividade de grãos, não foi constatada interação significativa entre os híbridos e as doses herbicidas estudadas. No entanto, houve efeito isolado do fator dose, significando que, na média de todos os híbridos avaliados, há efeito negativo da dose de $120 \mathrm{~g} \mathrm{ha}^{-1}$ sobre a produtividade do milho (Tabela 4). Por outro lado, evidencia-se também que o isoxaflutole na dose recomendada (60 $\left.\mathrm{g} \mathrm{ha}^{-1}\right)$ não oferece efeitos prejudiciais à produtividade, independentemente do híbrido considerado. Assim, é importante que o agricultor tenha cuidado no preparo da calda de pulverização, na tecnologia e no momento da aplicação desse herbicida, pois fatores como sobreposição de faixas de aplicação, velocidades inadequadas no deslocamento de pulverizadores e depósitos pontuais de calda de aplicação podem levar à aplicação de doses acima das toleráveis pela cultura.

Esses resultados estão de acordo com os apresentados por Rolim Pereira et al. (2001), que verificaram que o herbicida isoxaflutole

Tabela 2 - Altura das plantas (cm), em duas épocas de avaliação, de híbridos de milho submetidos à aplicação do herbicida isoxaflutole. Dados transformados em $\log (\mathrm{x})$ aos 28 dias após a aplicação (DAA), com a média original entre parênteses. Universidade Estadual de Maringá, Maringá-PR, 2007

\begin{tabular}{|c|c|c|c|c|}
\hline \multirow{2}{*}{$\begin{array}{l}\text { Épocas } \\
\text { (DAA) }\end{array}$} & \multirow{2}{*}{ Híbrido } & \multicolumn{3}{|c|}{ Dose $\left(\mathrm{g} \mathrm{ha}^{-1}\right)$} \\
\hline & & 0 & 60 & 120 \\
\hline \multirow{5}{*}{21} & Penta & $14,50 \mathrm{~A}$ & $12,00 \mathrm{AB}$ & $10,67 \mathrm{~B}$ \\
\hline & CD 304 & $15,17 \mathrm{~A}$ & $11,83 \mathrm{~B}$ & $9,83 \mathrm{~B}$ \\
\hline & OC 705 & $11,67 \mathrm{~A}$ & $11,17 \mathrm{~A}$ & $7,83 \mathrm{~B}$ \\
\hline & B 184 & $14,83 \mathrm{~A}$ & $12,67 \mathrm{AB}$ & $10,67 \mathrm{~B}$ \\
\hline & Garra & $18,50 \mathrm{~A}$ & $14,50 \mathrm{~B}$ & $12,67 \mathrm{~B}$ \\
\hline \multicolumn{5}{|c|}{$\mathrm{CV}(\%)=14,67$} \\
\hline \multicolumn{5}{|l|}{$\mathrm{DMS}=2,54$} \\
\hline \multirow{5}{*}{28} & Penta & $1,45 \mathrm{~A}(28,11)$ & $1,39 \mathrm{AB}(24,27)$ & 1,33 B $(21,15)$ \\
\hline & CD 304 & 1,46 A $(29,16)$ & $1,35 \mathrm{~B} \quad(22,58)$ & $1,31 \mathrm{~B}(20,40)$ \\
\hline & OC 705 & $1,39 \mathrm{~A}(24,81)$ & $1,40 \mathrm{~A} \quad(25,37)$ & 1,19 B $(15,56)$ \\
\hline & B 184 & $1,43 \mathrm{~A}(27,14)$ & $1,40 \mathrm{AB}(25,11)$ & 1,34 B $(21,64)$ \\
\hline & Garra & $1,56 \mathrm{~A}(36,35)$ & $1,47 \mathrm{~B} \quad(29,38)$ & 1,40 B $(25,18)$ \\
\hline \multicolumn{5}{|c|}{$\mathrm{CV}(\%)=4,10$} \\
\hline \multicolumn{5}{|l|}{$\mathrm{DMS}=1,39$} \\
\hline
\end{tabular}

Médias seguidas pela mesma letra na linha não diferem entre si pelo teste de Tukey a $5 \%$ de probabilidade. 
Tabela 3 - Diâmetro de colmo (mm) de híbridos de milho submetidos à aplicação do herbicida isoxaflutole aos 77 dias após a aplicação (DAA), com a média original entre parênteses. Dados transformados em $\log (\mathrm{x})$. Universidade Estadual de Maringá, Maringá-PR, 2007

\begin{tabular}{|c|c|c|c|}
\hline \multirow{2}{*}{ Híbrido } & \multicolumn{3}{|c|}{ Dose $\left(\mathrm{g} \mathrm{ha}^{-1}\right)$} \\
\cline { 2 - 4 } & 0 & 60 & 120 \\
\hline Penta & $1,19 \mathrm{~A}(15,55)$ & $1,19 \mathrm{~A}(15,37)$ & $1,18 \mathrm{~A}(15,25)$ \\
\hline CD 304 & $1,16 \mathrm{~A}(14,34)$ & $1,16 \mathrm{~A}(14,29)$ & $1,15 \mathrm{~A}(14,18)$ \\
\hline OC 705 & $1,17 \mathrm{~A}(14,68)$ & $1,16 \mathrm{~A}(14,51)$ & $1,11 \mathrm{~B}(12,83)$ \\
\hline B 184 & $1,17 \mathrm{~A}(14,68)$ & $1,14 \mathrm{~A}(13,85)$ & $1,14 \mathrm{~A}(13,65)$ \\
\hline Garra & $1,20 \mathrm{~A}(15,85)$ & $1,17 \mathrm{~A}(14,79)$ & $1,16 \mathrm{~A}(14,45)$ \\
\hline CV $(\%)=2,75$ & \\
\hline DMS $=0,04$ &
\end{tabular}

Médias seguidas pela mesma letra na linha não diferem entre si pelo teste de Tukey a $5 \%$ de probabilidade.

Tabela 4 - Produtividade de grãos (kg ha $\left.{ }^{-1}\right)$ de milho por ocasião da colheita de híbridos submetidos à aplicação do herbicida isoxaflutole. Universidade Estadual de Maringá, MaringáPR, 2007

\begin{tabular}{|c|c|c|c|}
\hline \multirow{2}{*}{ Híbrido } & \multicolumn{3}{|c|}{ Dose $\left(\mathrm{g} \mathrm{ha}^{-1}\right)$} \\
\cline { 2 - 4 } & 0 & 60 & 120 \\
\hline Penta & 6.521 & 6.280 & 6.234 \\
\hline CD 304 & 5.112 & 4.617 & 4.287 \\
\hline OC 705 & 4.720 & 4.842 & 4.337 \\
\hline B 184 & 4.986 & 5.127 & 4.746 \\
\hline Garra & 6.102 & 5.559 & 5.503 \\
\hline Média & $5.488 \mathrm{~A}$ & $5.285 \mathrm{AB}$ & $5.021 \mathrm{~B}$ \\
\hline CV (\%) $=12,83$ \\
\hline \multicolumn{4}{|l}{ DMS (doses) $=418$} \\
\hline
\end{tabular}

Médias seguidas pela mesma letra na linha não diferem entre si pelo teste de Tukey a $5 \%$ de probabilidade.

na dose de $60 \mathrm{~g} \mathrm{ha}^{-1}$ apresentou seletividade para todos os híbridos de milho avaliados: Z 8420, Z 8550, P 3027, C 333-B, AG 1051, C 747, BR 205, BR 106, BRS 3101, AG 6018, AL 25, BR 206, BR 473, AG 9010, BR 201, AL 34, XB 8010, DKB 350, SHS 4040 e AG 6690. Da mesma forma, Carvalho et al. (2000) também apresentaram resultados semelhantes após a aplicação do isoxaflutole na dose de $60 \mathrm{~g} \mathrm{ha}^{-1}$, concluindo que o herbicida apresentou seletividade aos cultivares de milho Exceler, Cargill 333 e P 3070.

O efeito prejudicial da dose de $120 \mathrm{~g} \mathrm{ha}^{-1}$ de isoxaflutole sobre a produtividade de grãos na média de todos os híbridos avaliados (Tabela 4), de modo geral, pode estar relacionado com as injúrias proporcionadas aos híbridos pelo herbicida, como: sintomas de fitointoxicação (Figura 1), redução de altura (Tabela 2) e diâmetro de colmo (Tabela 3). No entanto, outros componentes de produtividade não avaliados, como o número médio de fileiras de grãos por espiga e o número médio de grãos por fileira, podem, da mesma forma, estar explicando tal fato.

Ao contrário do ocorrido no experimento em casa de vegetação, onde foi possivel classificar os híbridos em diferentes niveis de sensibilidade ao isoxaflutole, no que se refere ao acúmulo de massa seca de parte aérea (Tabela 1), em campo não foi possivel identificar de forma específica híbridos que tenham sido afetados pelo herbicida, levando em consideração a produtividade de grãos (Tabela 4). Dessa forma, resultados obtidos em casa de vegetação não corroboram, necessariamente, resultados de experimentos conduzidos em campo, onde a principal variável-resposta avaliada é a produtividade de grãos. Desse modo, no presente trabalho, entre aqueles utilizados na etapa de campo, os híbridos Ocepar 705 e Penta, considerados de maior sensibilidade, o híbrido Garra, considerado de menor sensibilidade, e os híbridos B 184 e CD 304, considerados de sensibilidade intermediária em casa de vegetação, não apresentaram queda significativa de produtividade em campo para as mesmas doses herbicidas estudadas.

Contudo, é conveniente mencionar que, em se tratando do isoxaflutole, são poucos os trabalhos que pesquisaram a tolerância desse herbicida a genótipos de milho, necessitandose, portanto, de maior número de estudos visando obter mais informações.

\section{LITERATURA CITADA}

CARVALHO, J. A.; SANTOS, V. L. M.; SANTOS, C. M. Eficácia e seletividade de herbicidas na cultura do milho. In: CONGRESSO BRASILEIRO DA CIÊNCIA DAS PLANTAS DANINHAS, 22., 2000, Foz do Iguaçu. Resumos... Foz do Iguaçu: 2000. p. 262.

CEZARINO, V. Isoxaflutole - nova molécula herbicida para as culturas da cana-de-açúcar e do milho. In: CONGRESSO BRASILEIRO DA CIÊNCIA DAS PLANTAS

DANINHAS, 21., 1997, Caxambu. Palestras... Caxambu: Sociedade Brasileira da Ciência das Plantas Daninhas, 1997. p. 79-93. 
DEVINE, M.; DUKE, S. O.; FEDTKE, C. Physiology of herbicide action. Englewood Cliffs: Prentice Hall, 1993. $441 \mathrm{p}$.

EMPRESA BRASILEIRA DE PESQUISA AGROPECUÁRIA - EMBRAPA. Centro Nacional de Pesquisa de Solos. Sistema brasileiro de classificação de solos. Brasília: Embrapa Produção de Informação; Rio de Janeiro: Embrapa Solos, 1999. 412 p.

EZRA, G.; GRESSEL, J. Rapid effects of a thiocarbamate herbicide and its dichloroacetamide protectant on a macromolecular synthesis and glutathione levels in maize cell cultures. Pestic. Biochem. Physiol., v. 17, n. 1, p. 48-58, 1982.

FERREIRA, D. F. Sistema de análise de variância (SISVAR). versão 4.6. Lavras: Universidade Federal de Lavras, 1999. CD-ROM.

FERREIRA, L. C.; CATANEO, A. C. Aspectos bioquímicos da ação de "safeners". B. Inf. SBCPD, v. 8, n. 2, p. 5-6, 2001.

KRUSE, N. D. Inibidores da síntese de carotenóides. In VIDAL, R. A.; MEROTTO JR., A. Herbicidologia. Porto Alegre: Edição dos Autores, 2001. p. 113-122.

MITRA, S.; BHOWMILK, P. C.; XING, B. Sorption and desorption of the diketonitrile metabolite of isoxaflutole in soils. Environ. Poll., v. 108, n. 1, p. 183-190, 2000.

PALLET, K. E. et al. The mode of action of isoxaflutole. I. Physiological effects, metabolism, and selectivity. Pestic. Biochem. Physiol., v. 62, n. 1, p. 113-124, 1998.

RODRIGUES, B.N.; ALMEIDA, F.S. Guia de herbicidas. 5.ed. Londrina: 2005. 592 p.
ROLIM PEREIRA, F. A. et al. Estudo da seletividade de herbicidas em cultivares de milho (Zea mays L.), nas condições ambientais de Mato Grosso do Sul. Ensaios Ci. v. 5 , n. 2 , p. $119-140,2001$.

ROUCHAUD, J. et al. Isoxaflutole herbicide soil persistence and mobility in summer corn and winter wheat crops.

B. Environ. Contam. Toxicol., v. 60, p. 577-584, 1998.

SAS Institute. Statistical Analysis System Institute.

Procedure guide for personal computers. Version 5. Cary: 1999

SPRAGUE, C. L.; PENNER, D.; KELLS, J. J. Important considerations for RPA 201772 utility. Weed Technol., v. 13, p. $814-820,1999$ a

SPRAGUE, C. L.; PENNER, D.; KELLS, J. J. Physiological basis for tolerance of four Zea mays hybrids to RPA 201772 Weed Sci., v. 47, n. 4, p. 375-382, 1999b.

TAYLOR-LOVELL, S. et al. Hydrolisis and soil adsorption of the labile herbicide isoxaflutole. v. 34, n. 19, p. 31863190,2000

TAYLOR-LOVELL, S.; SIMS, G. K.; WAX, L. M. Effects of moisture, temperature, and biological activity on the degradation of isoxaflutole in soil. J. Agric. Food Chem. v. 50, n. 20 , p. 5626-5633, 2002.

VIDAL, R. A. Herbicidas: mecanismos de ação e resistência de plantas. Porto Alegre: R.A. Vidal, 1997. 165 p.

VIVIANI, F.; LITTLE, J. P.; PALLET, K. E. The mode of action of isoxaflutole. II. Characterization of the inhibition of carrot 4-hydroxyphenylpyruvate dioxygenase by the diketonitrile derivative of isoxaflutole. Pestic. Biochem. Physiol., v. 62, n. 1, p. 125-134, 1998.

YOUNG, B. G.; HART, S. E. Mobility of RPA 201772 in Setaria faberi. Weed Sci., v. 48, n. 2, p. 188-192, 2000. 